DOI (10.1108/IJES-11-2015-0023)

International Journal of Emergency Services

(- 24 month embargo period)

- $\quad$ Article accepted for publication on 3 March, 2016.

\title{
London's burning: \\ integrating water flow rates and building types into fire risk maps
}

Thomas Ronan and Richard Teeuw

\begin{abstract}
This study explores fire risk and preparedness, with regard to water flow rates and building types in London, focusing on Southall district. A land-use survey was carried out to identify water requirements for firefighting across the study area. Local fire hydrant flow rates were analysed, using measurements taken during 2013 and archive data held by the London Fire Brigade (LFB). A Geographical Information System, QGIS, was used to explore spatial relationships between fire hydrant flow rates, urban fire risk and socio-economic vulnerability data held by the LFB. The LFB vulnerability maps are primarily based on socio-economic vulnerability: at many locations they were found to yield underestimates of fire risk. A new type of map, which includes data on water flow rates and building types, was created using QGIS and applied to Southall district, resulting in a map showing Combined Vulnerability to fires. Inadequate firehydrant water supply was found across many parts of the borough. Temporal variations in fire occurrence and water supply are examined, from daily through to seasonal variations, with consideration of the impacts of climate change. Recommendations are made for adaptations to urban fire resource allocation, tactics, planning and preparedness.
\end{abstract}

Key words: Firefighting, Fire Risk, Vulnerability, Water Supply, Hydrants, London, GIS.

\section{Introduction}

Successful firefighting requires immediate access to adequate supplies of water. The access to, and proximity of, those water supplies directly affects the resources and tactics firefighters can 
deploy at an incident (Local Government Association \& Water UK, 2007). Fire hydrants in the public water distribution system ('water mains') are located across London to facilitate the provision of water for firefighting. In recent years water supply companies have reduced pressure and flow in London water mains, to reduce leakage. Pressure and flow also vary on a daily basis, because water companies reduce supply at times of low demand, particularly at night (London Fire Brigade (LFB), 2012c).

Assessing the variability of water supply within London, and the effect that this has on community vulnerability, is a component of fire management that is inadequately understood. This study provides some new insights, examining the following research questions:

\section{Are there clear spatial and temporal variations in mains water supply within London?}

2. Could variation in water supply within London affect the vulnerability of residents to fires?

3. What are the fire management implications of water supply variation, on fire risk, vulnerability and preparedness?

This study has produced an innovative map of combined fire vulnerability, based on land use (building) vulnerability, water supply vulnerability and socio-economic vulnerability. The methodology can be used as a template for producing combined fire vulnerability maps of other London districts, with potential application in other cities.

\subsection{Water requirements for firefighting}

In their guidance document for fire and rescue services, the UK Department for Communities and Local Government (DCLG, 2011) state that the flow of water available from fire hydrants may be as little as 9 litres per minute, well below the level required to supply an effective firefighting jet. This level of provision is nevertheless well above the statutory minimum that UK water companies must provide to domestic consumers. The DCLG document states that even the 9 litres per minute rate of flow cannot be assumed to be always available, and that climate change provides the potential for significant disruption to water supplies, including 
the availability of water for firefighting. However, the availability of adequate water for firefighting purposes is an issue that may not be adequately considered within fire service strategic planning (DCLG, 2011).

There is a shared duty, under the UK Fire and Rescue Services Act (2004), between fire authorities and water utility companies, to secure the provision of water supplies for firefighting purposes. Water companies are obliged to provide a mains water supply and fire authorities are responsible for determining the location of hydrants, their testing, repair and maintenance (DCLG, 2011). Despite this shared duty, there is an apparent disparity between the high demands placed on the water mains system during fire incidents, and the variable and limited supply available from the water mains. It may be operationally necessary for the fire service to consider securing greater supplies of water than those immediately available from the nearest hydrant (DCLG, 2011), or to consider the adoption of flexible policies and tactics that reflect the local water supply.

The variable nature of London's domestic water supply has implications for the provision of adequate water for firefighting, particularly the development of policies and tactics for response and preparedness. For instance, if insufficient water is available for firefighting, or if fire service policies and tactics cannot accommodate variable water supply, then the ability of operational crews to respond to a fire is reduced. Likewise, true preparedness cannot be achieved if operational crews are unaware of the likely water resources that they will have at their disposal. In the context of sustainable development, consideration must be given to water supplies for firefighting in the planning stages of residential developments, particularly those involving highrise premises or large basements, which tend to have a demand for water that is greater than the amount provided by the domestic water main.

There are direct and indirect risks associated with a failure to provide or secure adequate water for firefighting. Direct risks include increased risk of injury or death for occupants of affected buildings and of firefighters responding to incidents; the loss of building contents and of the Page | 3 
building itself; the rapid spread of fire between buildings, leading to multiple losses; and economic risks associated with business interruption, such as loss of revenue and employment. Indirect risks of inadequate water supply include a reluctance from insurers to pay claims or to provide fire insurance cover in areas known to have poor provision, or of significantly increased premiums in these areas. In addition to an increased insurance risk, owners or managers of buildings that have insufficient water available for firefighting are at risk of legal action, in the event of significant losses occurring (Dalrymple, 2007).

A routine urban fire can escalate into a more dangerous incident, if the available water supply does not match the level required for firefighting. Ensuring that the correct water resources are available to tackle fires offensively is therefore essential in planning the London's fire and rescue cover. Deficiencies in water availability in one area will not only have an impact on fire cover, but also the response to incidents throughout London, as more appliances are drawn in to deal with escalating fires. The case study summarised in Table 1shows how an incident can escalate and draws in firefighting resources, if insufficient water is available on the initial attendance. Incidents of this type have implications for resilience and business continuity for London Fire Brigade, due to the impact they have on the availability of resources for firefighting and rescue across London.

\begin{tabular}{|l|l|}
\hline \multicolumn{2}{|l|}{ Table 1. Case study: a commercial fire with insufficient water for firefighting, } \\
February 2013 (London Fire Brigade, 2013a) \\
\hline $\begin{array}{l}\text { Time } \\
\mathbf{2 1 : 1 5}\end{array}$ & $\begin{array}{l}\text { Fire reported in a workshop. } \\
\text { Three fire appliances dispatched, in line with pre-determined attendance plan for } \\
\text { fires of this type. }\end{array}$ \\
\hline $\mathbf{2 1 : 2 1}$ & $\begin{array}{l}\text { Incident commander requests an additional appliance, due to reports of persons } \\
\text { trapped in the building. } \\
\text { Two members of the public rescued by firefighters and received treatment from } \\
\text { London Ambulance Service. }\end{array}$ \\
\hline $\mathbf{2 1 : 2 8}$ & $\begin{array}{l}\text { Two further appliances requested. } \\
\text { availability for firefighting; gas cylinders confirmed involved in the fire. }\end{array}$ \\
\hline
\end{tabular}




\begin{tabular}{|c|c|}
\hline 21:53 & $\begin{array}{l}\text { Hose-laying appliance requested to allow the firefighting water supply to be } \\
\text { augmented by water pumped from up to } 1 \mathrm{~km} \text { from the site of the fire. }\end{array}$ \\
\hline 21:59 & liances requested, bringing the total attendance to ten. \\
\hline 22:07 & $\begin{array}{l}\text { The urgent attendance of a Thames Water turncock requested, to increase the } \\
\text { supply of water in the area. }\end{array}$ \\
\hline 22:13 & $\begin{array}{l}100 \% \text { of original building alight. } \\
\text { Firefighters use two ground monitors, each with a minimum water usage of } 900 \\
\text { litres per minute (lpm) and } 4 \text { jets, each with a minimum water usage of } 115 \mathrm{lpm} \text {, to } \\
\text { tackle the fire: giving a combined demand on the local water main of } 2260 \mathrm{lpm} \text {. }\end{array}$ \\
\hline 22:15 & $\begin{array}{l}100 \text { meter exclusion zone implemented around the fire, due to the gas cylinders } \\
\text { involved. Approximately } 100 \text { people evacuated from homes in the area. }\end{array}$ \\
\hline 22:23 & $\begin{array}{l}\text { A further message sent to Thames Water repeating the request for an increase in } \\
\text { water pressure, this time for } 1 \mathrm{~km} 2 \text { around the site. }\end{array}$ \\
\hline 23:20 & $\begin{array}{l}\text { The fire has spread from the workshop to an adjacent industrial unit, which } \\
\text { suffered } 100 \% \text { damage, and to the roof of a two-storey residential building which } \\
\text { suffered } 5 \% \text { damage. The gas supply to the workshop was also compromised in } \\
\text { the fire, leading to further damage and required the shutting-off of the main gas } \\
\text { pipe to the street. }\end{array}$ \\
\hline 11:35 & \\
\hline
\end{tabular}

When considering the requirements of water for firefighting, it should be recognised that distribution systems are subject to a number of influences, some of which are beyond the control of water companies. Changes to water pressure, due to variation in demand and consumption at one point in the system, may cause peaks and troughs in supply over a wider area. Short term demands from high industrial use and illegal use of hydrants can also affect the capacity of the system. Seasonal variations in water availability include drought and flood conditions, both of which affect the ability of the system to supply water. Over the longer-term, changes in domestic and industrial use, as well as new connections to the water main, needed to supply the new development, also affect water availability (DCLG, 2011). These variations in water availability have serious implications for firefighting: there are minimum water supply requirements, below which firefighters will be unable to extinguish a fire. 
Defining what constitutes an adequate supply of water for firefighting, and whether it is available from the local water main, is central to planning fire service operations and is linked to the operational tactics of the firefighters (Davis, 2000; Benfer,and Scheffey, 2014; Grimwood, 2014). Several authors have attempted to quantify the volumes of water required to extinguish fires of various sizes. For instance, Sardqvist, (1996) highlights the heat absorption effect of water as being the process by which most fires are extinguished: a water supply of 1 litre per second ( lps) would theoretically be sufficient to extinguish a fire producing 5 mega joules (MJ) of energy per second. Using this approach in fire service planning is problematic, as the fire size and energy of fires encountered by firefighters at incidents is affected by many unknowable variables, including the time between ignition and notification of the fire service, fire service travel time, fire loading within a structure, fuel and accelerants within a structure, weather conditions, level of ventilation and size of fire cell. It is therefore not possible to use simple calculations of heat output to plan water resources, or to measure the sufficiency of a fire hydrant water supply, as this resource will be utilised to fight fires of many different sizes and at different stages of development. The UK Local Government Association and Water UK (2007) outlined recommended water availability for firefighting, for various land use classes. These recommendations are based on a risk assessment methodology that includes estimates fire loading and fire risk within different categories of buildings, summarised in Table 2.

Table 2. Land use and recommended fire hydrant flow rates, in litres per minute (lpm) Source: Local Government Association \& Water UK (2007)

\begin{tabular}{|l|c|}
\hline Land Use & $\begin{array}{c}\text { Recommended } \\
\text { flow (lpm) }\end{array}$ \\
\hline Housing & 480 \\
\hline Low residential: detached or semidetached houses of less than two floors & $1200-2100$ \\
\hline High residential: multi-occupancy housing, units of more than two floors & \\
\hline
\end{tabular}




\begin{tabular}{|l|c|}
\hline Transportation & \\
\hline Lorry/coach parks - multi-storey car parks - service stations & 1500 \\
\hline Industry & 1200 \\
\hline Sites of up to one hectare & 2100 \\
\hline Sites of between one and two hectares & 3000 \\
\hline Sites of between two to three hectares & 4500 \\
\hline Sites of over three hectares & $1200-4500$ \\
\hline Shopping, offices, recreation and tourism & \\
\hline Education, health and community facilities & \\
\hline Village halls & \\
\hline Primary schools and single storey health centres & \\
\hline Secondary schools, colleges, large health and community facilities & 2100 \\
\hline At Certain incidents, such as basement fires and high-rise fires, amim \\
\hline
\end{tabular}

At certain incidents, such as basement fires and high-rise fires, a minimum weight of attack is stipulated by London Fire Brigade (LFB: 2008a, 2011a, 2012a). "Minimum weight of attack", refers to the types of firefighting media that crews are expected to use when making entry into the risk area of an incident. The weight of attack will directly influence the demand on the water supply, as each firefighting medium uses a different volume of water when producing a firefighting jet. If the water available does not support the minimum weight of attack, the firefighter is unable to implement the safe system of work and should not enter the risk area of the incident. This will force the incident commander to adopt defensive firefighting tactics, putting water on the fire from outside the risk area, rather than taking offensive actions to enter the burning structure and extinguish the fire from the inside. The minimum weights of attack required by the London Fire Brigade when dealing with basement, compartment and high-rise fires are given in Table 3, with the associated water supply requirements. For smaller, or less hazardous fires, crews have access to high pressure hose reels that have an operational flow range of $35-150 \mathrm{lpm}$, this equipment allows crews to attack a fire with less water usage; 
however, it is not LFB policy for high pressure hose reels to be used in high-rise, basement or compartment fires (LFB, 2008b).

Table 3. Minimum weights of attack for London Fire Brigade operations.

\begin{tabular}{|l|l|l|}
\hline Type of Fire & Minimum Weight of Attack & $\begin{array}{l}\text { Total Water } \\
\text { Requirement }\end{array}$ \\
\hline Basement fire & $2 \times 45 \mathrm{~mm}$ hose jets adjusted to $230 \mathrm{lpm}$ flow rate & $460 \mathrm{lpm}$ \\
\hline Compartment fire & $1 \times 45 \mathrm{~mm}$ hose jet adjusted to $230 \mathrm{lpm}$ flow rate & $2301 \mathrm{pm}$ \\
\hline High-Rise fire & $\begin{array}{l}2 \times 45 \mathrm{~mm} \text { hose jets adjusted to } 115 \mathrm{lpm} \text { or } 230 \mathrm{lpm} \\
\text { if compartment conditions encountered }\end{array}$ & $230 / 460 \mathrm{lpm}$ \\
\hline
\end{tabular}

Should firefighters encounter basement fire conditions with a hydrant supply of less than 460 lpm, compartment fires with a supply of less than $230 \mathrm{lpm}$; or combined compartment and high rise fires with a supply of less than $460 \mathrm{lpm}$, then LFB policy will prevent them from tackling the fire offensively: tactics will revert to defensive firefighting. When assessing the sufficiency of the water supply available in an area, factors such as the extinguishing and cooling effect of water have to be considered against the energy outputs from fires, alongside the likely fire loading of structures within an area. In this study, sufficiency of water supply is assessed against the guidelines of Local Government Association \& Water UK, (2007): these include estimates of fire loading, fire risk within structures and the minimum weights of attack for different classes of fire, as these represent likely operational usage by crews implementing their safe system of work.

\subsection{Measuring risk and vulnerability for urban fire hazards}

The UNISDR (2007) defines vulnerability as, "the characteristics and circumstances of a community, system or asset that make it susceptible to the damaging effects of a hazard." Vulnerability has many aspects, arising from physical, social, economic, and environmental factors. Vulnerability to hazards will be influenced by: the construction standards of buildings, the level of public awareness regarding hazards, the preparedness measures undertaken by communities and the standard of local services and infrastructure. This definition identifies 
vulnerability as a characteristic of the community, which is independent of its exposure to a given hazard and can vary significantly within a community and over time, as the above factors change (UNISDR, 2007).

Vulnerability to urban fires, is strongly linked with socio-economic factors. People living in lowcost housing are often made vulnerable to urban fire hazards by the age and state of repair of the buildings in which they live. Housing of low-income persons is prone to faulty electrical services and aging utilities; while their accommodation tends to be densely distributed, increasing the risk of fire spreading rapidly. Housing in low-income neighbourhoods is also more likely to have inadequate firewall protection and to lack fire detection and sprinkler systems (City of Kent, 2010).

Factors influencing the rate of fires in dwellings have also been identified as strongly socioeconomic. Concentration of single parent families within a community has been highlighted as being a strong predictor of an increased rate of dwelling fires, accounting for $63.7 \%$ of the variance between communities. Rented accommodation, lone pensioners and the presence of people with long term limiting illnesses, are also linked to a higher risk of dwelling fires (DCLG, 2008). Smith, Write \& Solanki, (2007) identified five socio-economic and demographic factors associated with both a higher risk of experiencing a fire and also with the risk of being injured or killed by a fire. These factors were: being single, having a high score on the UK multiple index of deprivation scale, having a mental or physical impairment, careless use of smoker's materials and alcohol usage. Wright \& Genna, (2005) found that $77 \%$ of all victims of fire were impaired through substance misuse, or through a physical or mental impairment.

Within low-income areas, housing density may be increased further through the development of informal dwellings, such as sheds and out-houses constructed in back gardens and used for accommodation (Govender, Barnes \& Pieper, 2011). Fire risks in informal developments such as these are higher, due to reliance on improvised methods of cooking, lighting and heating. Informal dwellings are becoming common within London, increasing fire risks in communities Page | 9 
already at risk due to socio-economic deprivation (Rogers, 2012). In Southall (west London) $60 \%$ of private dwellings have outbuildings and sheds used as informal dwellings, of which $10 \%$ (2500 buildings) contain illegal occupation (Gilmore \& Smith, 2012).

\subsection{Fire risk, vulnerability and preparedness within the London Fire Brigade (LFB)}

In London, areas with a higher level of fire risk and vulnerability are known as "Priority One Postcodes" (P1 Postcodes). These areas are where specific socio-demographic and geographic risk factors fit the criteria associated with an increased risk of an accidental domestic fire (LFB, 2011b). The London Fire Brigade identified these vulnerable and high-risk areas by comparing statistics on fire incidences and injuries with social and demographic data from the Mosaic Lifestyle Profile Service. The number of incidences of fire and injury were then compared with types of lifestyle present in each postcode zone, allowing a model to be developed of the types of people who experience the most fires. The Priority One measure takes account of differing vulnerability factors involved in fire risk, such as type of housing, level of socio-economic deprivation and demographics, to map postcodes that carry a high fire risk (LFB, 2013b). Figure 1 shows the distribution of Priority One (P1) postcodes in London.

\subsection{Water supply as a vulnerability factor}

Although the P1 system of vulnerability mapping includes socio-economic and demographic data, it does not include water supply or access to water for firefighting. In areas where water supply is low, firefighting is likely to be less effective, with firefighters are likely to default to defensive firefighting tactics; losses are likely to be higher, increasing vulnerability and fire risk through lack of response capability. This may make areas currently viewed as low risk, based on socio-economic measures, more vulnerable than they appear. Further, where areas of low water supply coincide with P1 postcodes the existing high levels of vulnerability and fire risk are likely to be exacerbated by a reduced response capability. Where demand on water supply for firefighting is likely to be significant in the event of a fire, an insufficient water supply is a significant vulnerability factor, potentially leading to greater levels of economic loss and Page | 10 
business interruption.

\subsection{The effect of unknown water supply variability on fire brigade preparedness}

Preparedness, within the context of community risk reduction, relates to activities carried out to build capacity to efficiently manage, anticipate, respond to, and recover from, the impacts of hazards and emergencies (UNISDR, 2007). Preparedness is essential to ensure an efficient emergency response and requires a sound analysis of risks and vulnerabilities to guide emergency planning and the positioning of resources (UNISDR, 2007). Within the London Fire Brigade (LFB), vulnerability has been mapped using socio-economic data, this is used as a guide to planning and the positioning of response resources (London Fire Brigade, 2013a). However, the vulnerability of communities due to water supply variations is not included in the current LFB fire risk analysis, potentially leading to inadequate planning and a mis-match of resources.

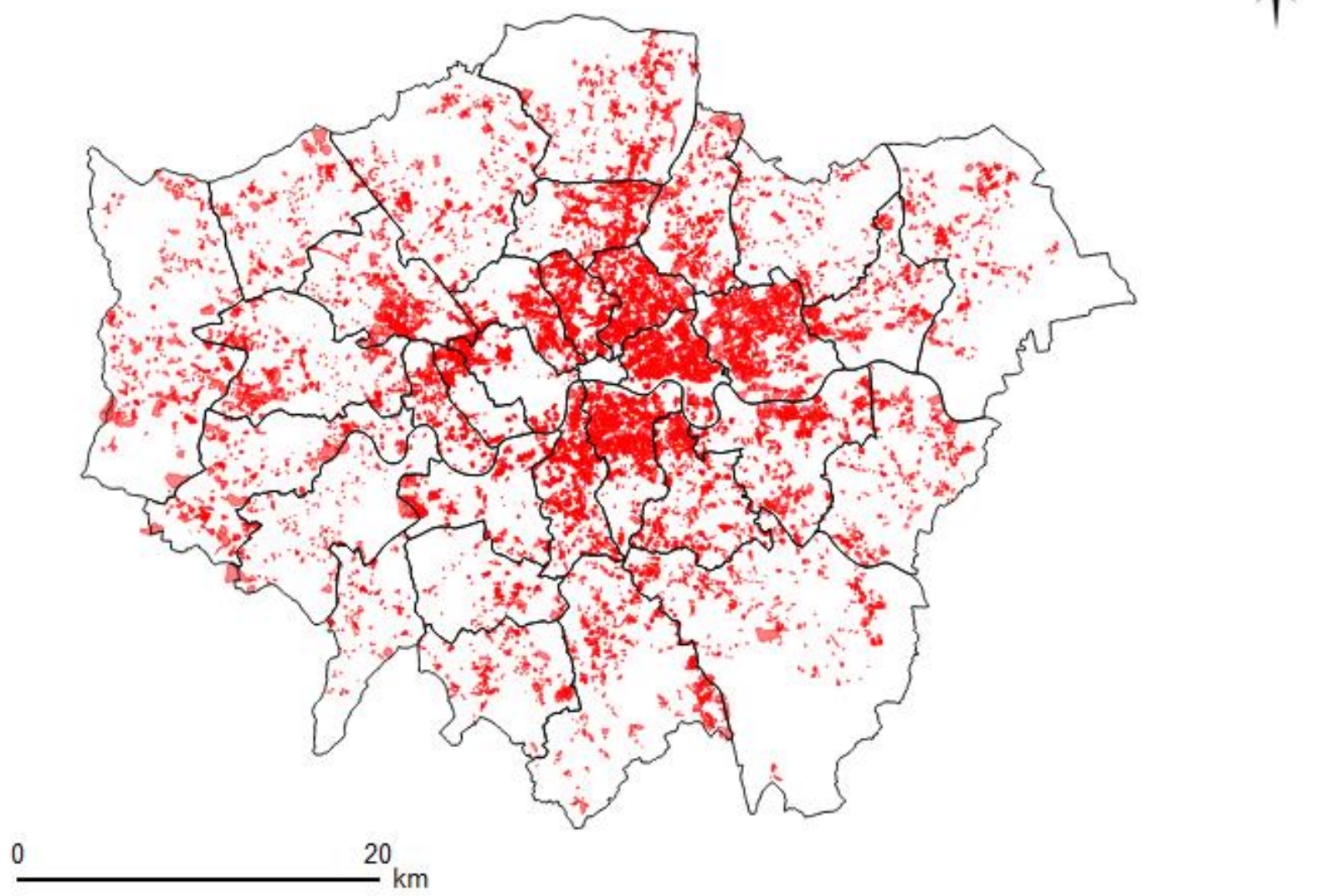

Figure 1. Areas of socio-economic vulnerability (red) in London, based on the Priority One

(P1) postcode classification used by LFB; also shown are the boundaries of the Page | 11 
administrative boroughs (source: London Fire Brigade).

\section{Methodology}

\subsection{Study area}

The district assessed by this study is Southall, north-west London, and covers $22 \mathrm{~km}^{2}$. Southall has a variety of fire risk areas, both of commercial and residential types, with many high-rise buildings of up to 14 floors, many illegal dwellings and a relatively large number of fires, typically 516 per year (London Fire Brigade, 2011b).

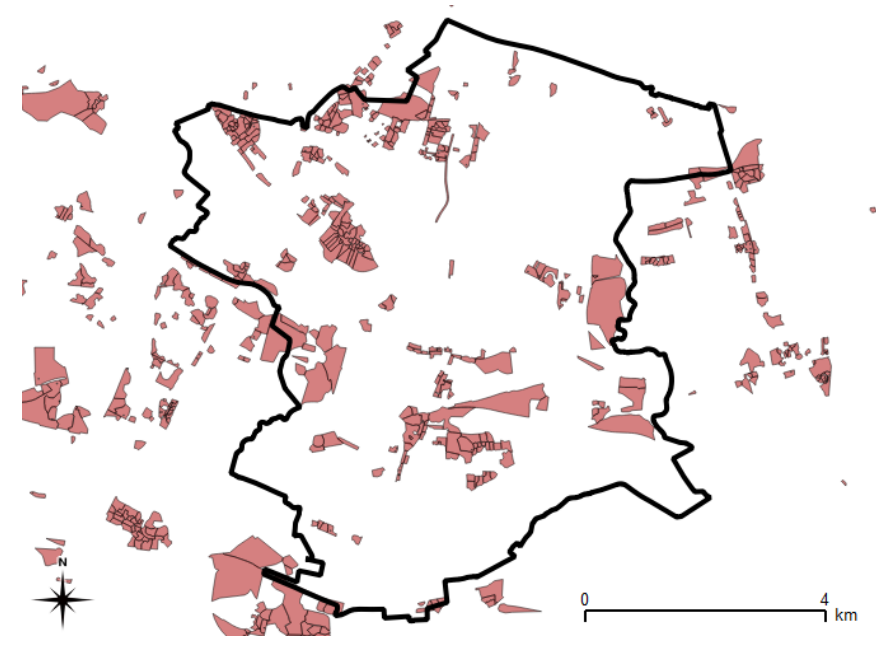

Figure 2. Southall: shaded areas have high socio-economic vulnerability (P1 postcodes). (source: London Fire Brigade)

Figure 2 shows areas in Southall with high socio-economic vulnerability (the "P1" postcodes of London Fire Brigade). The interaction of severe community vulnerability with areas that are vulnerable due to variations in water supply is examined here, to identify firefighting water requirements. Water supply data was obtained by the sampling of fire hydrants and through analysis of archive data from London Fire Brigade. QGIS (www.qgis.com) was selected for data analysis and mapping because it is free Geographical Information System (GIS) software. QGIS is compatible with data formats of the London Fire Brigade mapping system; it enables mapping, spatial analysis and visualisation of the many diverse datasets needed to assess fire risk. 


\subsection{Data}

(i) The land use survey of the Southall test area consisted of a visual identification of land use and building types, with categories adapted from Table 2,produced using data from Bing Maps, Open Street Map and Google Earth, with verification from Google Street View and 'groundtruth' observations by the lead author. . Each area was categorised according to predominant land use and recommended firefighting water flow rates. Because there is no category for terraced housing in the Local Government Association \& Water UK (2007) recommendations, housing in this category has been amalgamated with the land-use category, "Detached or semidetached houses of not more than two floors", used by the Local Government Association and Water UK (2007) to form the category: "Residential, fewer than three floors." Information on land use and recommended hydrant flow rate was then uploaded to QGIS for spatial analysis, mapping and comparison with water supply data collected by the fire hydrant sampling.

(ii) London Fire Brigade data. Measurements of fire-hydrant flow rates were made at hydrants across the study area. The directly collected data were combined with LFB archive data from hydrant testing in 2013, to achieve a wide spread of sample points. Non-operational sampling was carried out by trained firefighters using a LFB flow gauge (Figure 3).

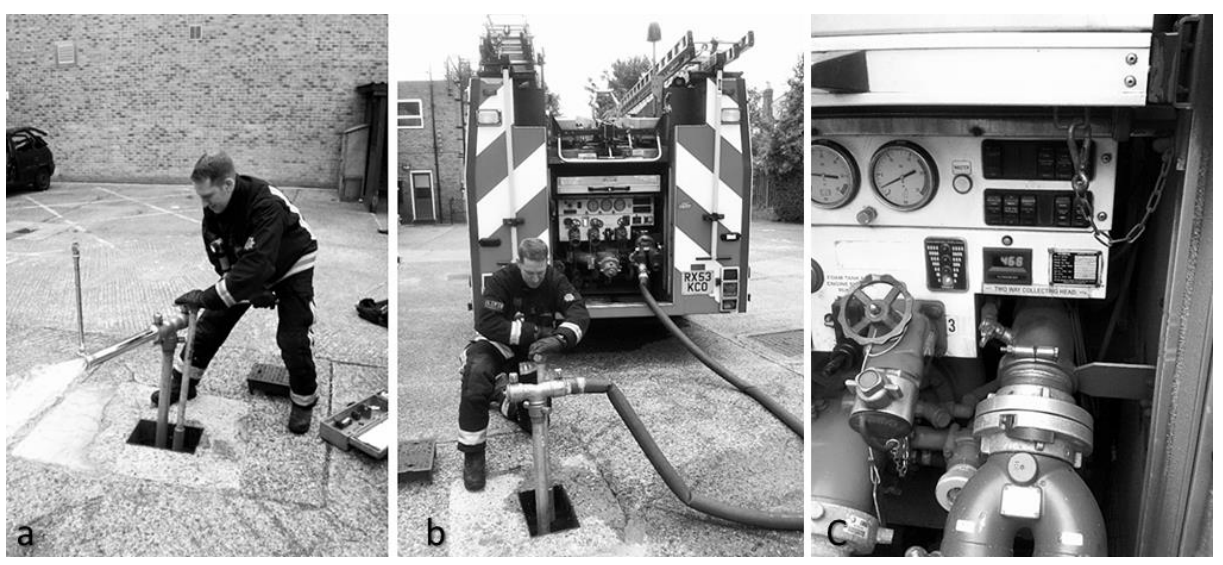

Figure 3. Testing water pressure via fire hydrants: (a) firefighter testing a hydrant, (b) fire appliance supplied from a hydrant; (c) flow gauge showing flow rate of the hydrant.

\subsection{Geospatial analysis and mapping}

Data from Southall fire hydrant water flow sampling and the LFB Water Office archive for fire hydrant flow rates in the study area, were compiled in a spreadsheet and uploaded to QGIS. This Page | 13 
data set, containing all the known water supply values for fire hydrants in the study area was used to produce a colour coded map showing fire hydrant water supply variation, using Inverse Distance Weighting Interpolation. This method was selected, to provide an illustration of water supply for locations in the study area, based on the known water supply value of the nearest fire hydrants. Using this method, locations surrounded by several hydrants with low water output are highlighted as poor water supply areas, reflecting the operational difficulties presented by such locations.

\subsection{Geospatial analysis of interactions between vulnerability features}

QGIS was used to analyse relationships between the land use, fire hydrant water supply and the LFB vulnerability data. Areas with the highest level of vulnerability are those where: (i) The land use type is likely to place a high demand on firefighting water supplies; (ii) P1 postcodes dominate, indicating high levels of socio-economic vulnerability;(iii) fire hydrant water supply is poor. Using those factors, a new map was created for the study area, showing Combined Vulnerability. The Combined Vulnerability was assessed by adding each data set as a map layer; where vulnerability factors overlapped, a detailed visual analysis of all map features was undertaken to explore the interaction between the vulnerability factors. A professional judgement was then made regarding the areas of highest vulnerability.

\section{Results}

The variations in flow rates at water hydrants in Southall district are shown in Figure 4; a map of land use types, modified to fit the categories for recommended firefighting water flow rates (Local Government Association \& Water UK, 2007) is shown in Figure 5. Figure 6 is an example of the resulting Water Supply Vulnerability maps, showing the land-use, socioeconomic vulnerability (P1 postcodes) and fire hydrant water supply layers, with individual flow rates visible for hydrant data points

\subsection{Water supply}


595 fire-hydrant water flow samples from 2013 were included in the analysis: $45 \%$ of the 1311 fire hydrants in the study area. This includes 57 fire hydrants tested locally and 538 for which the LFB had archive data. A substantial number of the sampled fire hydrants were found to be defective and in-operable: $11 \%$ and $19 \%$ in the LFB archive and local samples respectively. Those hydrants were allocated nominal flow rates of zero lpm. The interpolated water supply from fire hydrants in the study area is shown in Figure 4.

\section{Water Supply}

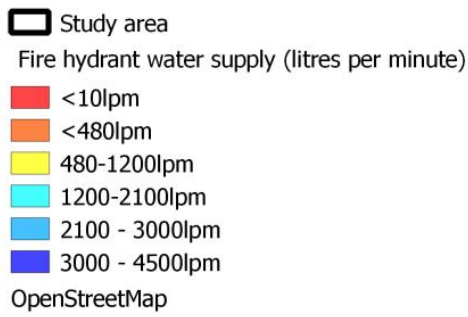

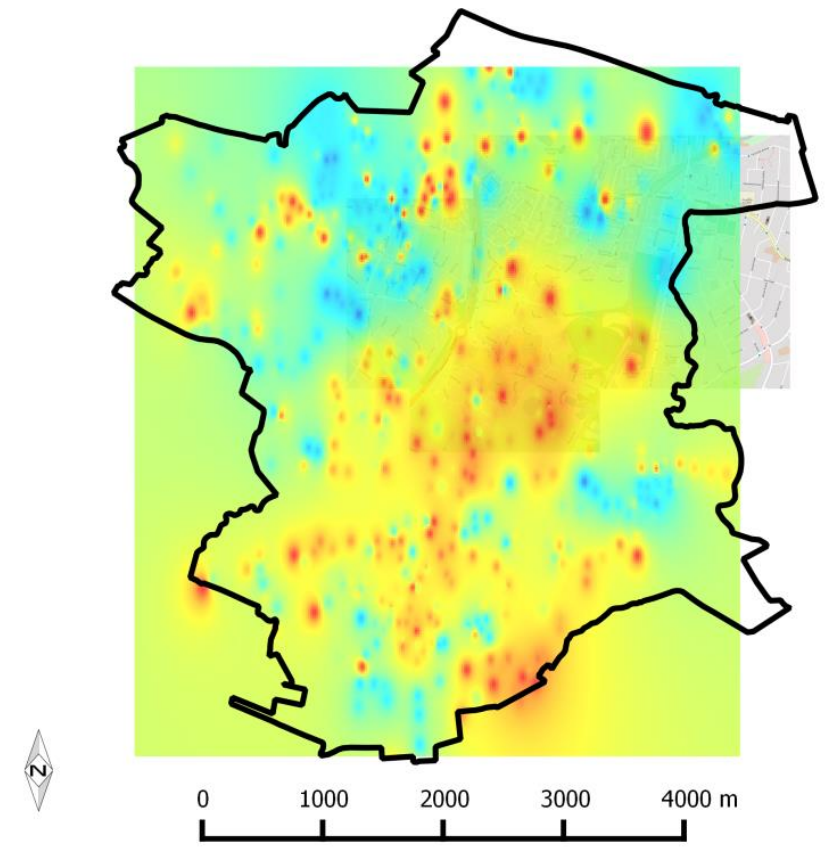

Figure 4. Water pressure in Southall, interpolated from fire hydrant sampling:values in litres per minute, lpm (source of base map: Open Street Map). 


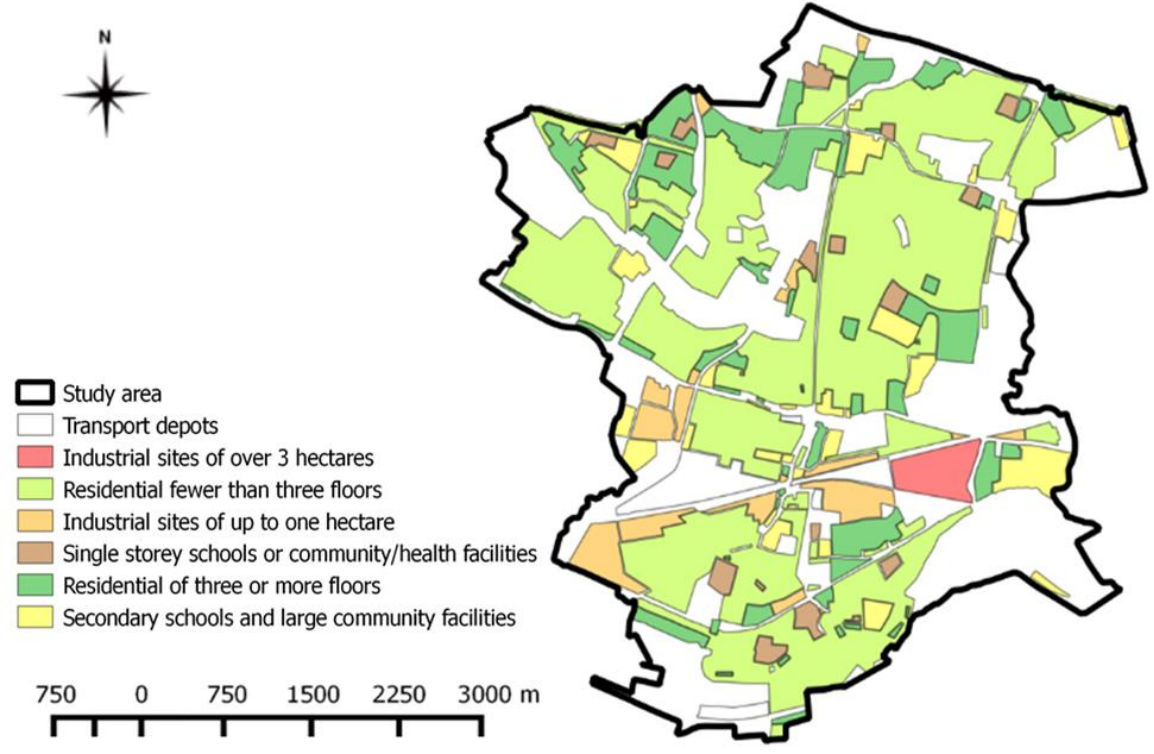

Figure 5. Land use types, modified to fit the recommended firefighting water flow rates (source of base map: Open Street Map).

\subsection{Geospatial analysis of interactions between vulnerability features}

The map of land use types, modified to fit the categories for recommended firefighting water flow rates (Local Government Association \& Water UK, 2007) is shown in Figure 5. QGIS was used to analyse relationships between the land use, fire hydrant water supply and the LFB vulnerability data. Figure 6 is an example of the resulting Water Supply Vulnerability maps, showing in detail the land-use, socio-economic vulnerability (P1 postcodes) and fire hydrant water supply layers, with individual flow rates visible for hydrant data points. 


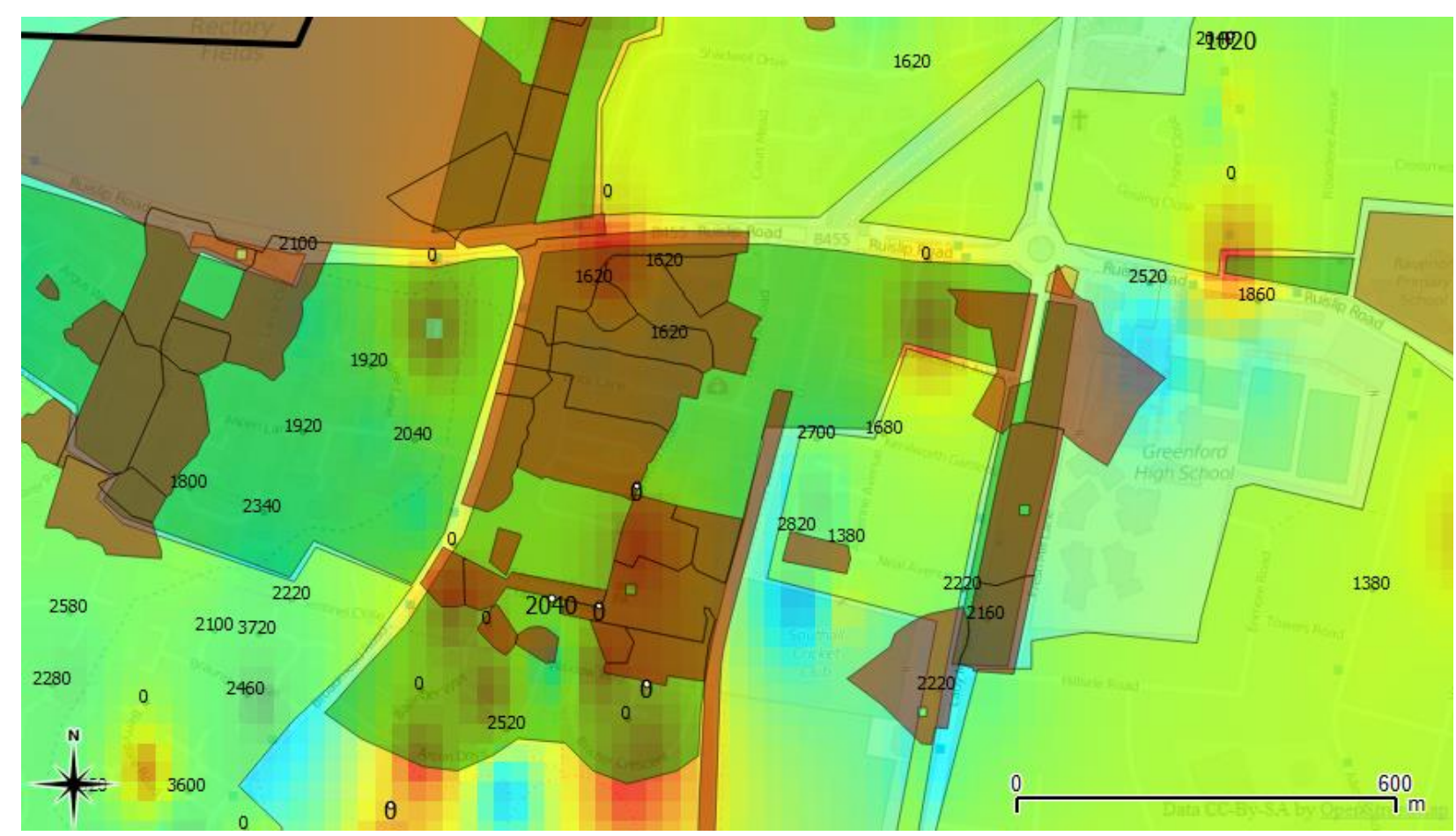

Figure 6. Water Supply Vulnerability map for part of Southall. Each numbered black dot is an individual fire hydrants and its sampled water pressure in litres per minute (source of base map: Open Street Map).

By examining the relationships between the different features visible in the GIS maps, areas with overlapping vulnerabilities were highlighted. Areas with the highest level of vulnerability are those where: (i) The land use type is likely to place a high demand on firefighting water supplies; (ii) P1 postcodes dominate, indicating high levels of socio-economic vulnerability;(iii) fire hydrant water supply is poor.

\subsection{Combined Vulnerability Map}

The Combined Vulnerability Map provides a better understanding of vulnerability to fire losses than the P1 postcode vulnerability maps used by London Fire Brigade and is being used to inform recommendations for improvements in preparedness and response. Within Southall, 13 areas were identified as having significant levels of Combined Vulnerability. Those areas were then assigned medium, high or very high combined vulnerability, based on the number of overlapping vulnerability features and the likely impact that those features will have on the Fire Brigade operational response (Figure 7). 


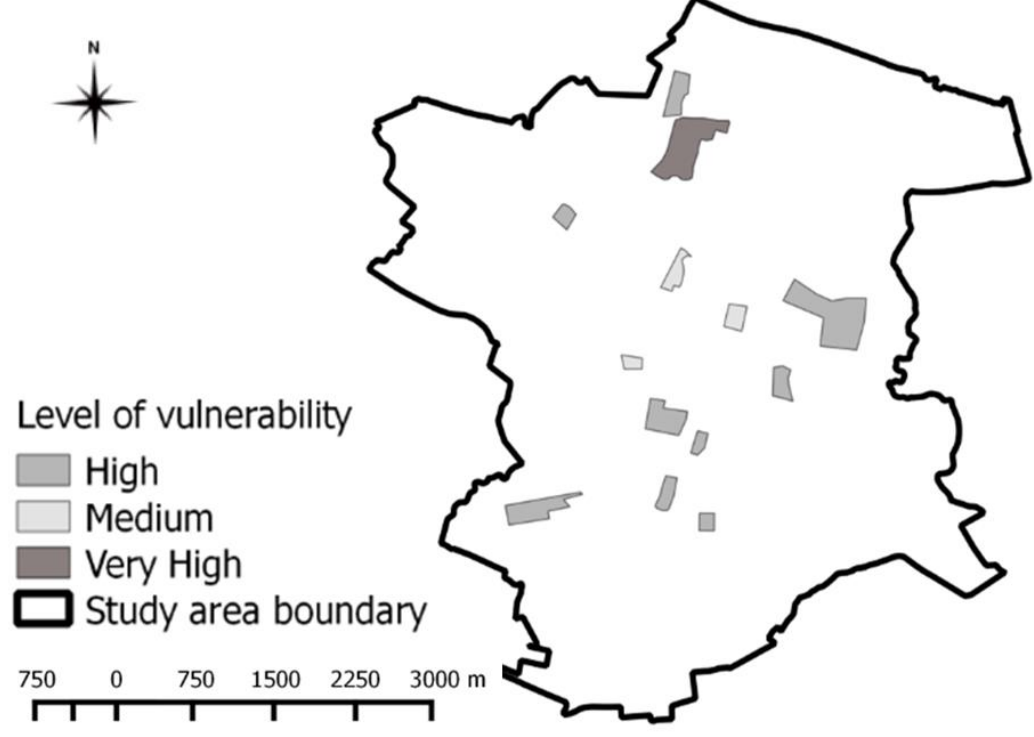

Figure 7. Combined Vulnerability map for Southall (source of base map: Open Street Map).

\section{Discussion}

\subsection{Fire risk areas highlighted by the Combined Vulnerability map.}

There are high levels of socio-economic vulnerability within the study area, as illustrated by the LFB's existing Priority One (P1) vulnerability map. This study has improved the understanding of fire vulnerability within Southall district, by comparing the existing P1 vulnerability map with the new map layers for fire hydrant water supply and the land use categories (each with their associated firefighting water requirements). The resulting Combined Vulnerability map provides an easy way to visualise areas of fire risk, where land use vulnerability and water supply vulnerability coincide with socio-economic (P1) vulnerability.

The Combined Vulnerability map highlighted problems with the mapping fire risk when using on socio-economic data, as with the LFB's use of P1 postcodes. The fire risk of some non-P1 areas was underestimated, due to the low socio-economic vulnerability of residents, even though those areas had a high water supply or building-type vulnerability. The Combined Vulnerability Map corrects this by taking into account water supplies and the large firefighting water 
requirements of some building types, as factors affecting vulnerability: these were previously "unknown but significant" variables. The underestimation of vulnerability to fire has implications beyond the study area, as $\mathrm{P} 1$ postcodes are used to target fire prevention and community fire safety work throughout London.

A surprising finding of this research was the high proportion of fire hydrants in the study area that were found to be defective. When the data points were mapped, the clustering of inoperable hydrants in some areas produced very high vulnerability, due to the impact of those inoperable hydrants on the ability of firefighters to respond to incidents in the area and their ability to adopt safe tactics. In some areas fire-hydrants were operable, but the flow rates were significantly below recommended levels and would not support minim weights of attack. In areas of high socio-economic vulnerability, the lack of fire-hydrant water supply further increases the vulnerability of residents, due to inoperable hydrants or low flow rates.

\subsection{Temporal variations in water supply}

Of the 57 hydrants tested locally during fire deployments, 54 were tested between 1100 and 1700. The LFB archive data did not include the times when the readings were taken, however it is unlikely that the sampling was undertaken outside of normal working hours (ie, between 0900 and 1700). Ofwat (2013) state that domestic demand for water is highest in the early mornings and evenings and that domestic water pressure consequently tends to be lower at those times. As the domestic water main is also the water supply used for firefighting, it is likely that this temporal variation in water pressure will be mirrored in fire-hydrant flow rates. That is borne out by a review of London's fire hydrant water supply (LFB, 2012c), which found significantly lower flow in the early mornings, evenings and at night, than during the day. It is therefore likely that the figures for fire hydrant flow rates recorded in this study represent the higher range of values expected from fire hydrants over the course of a day, and that the vulnerabilities highlighted by this study will be more even pronounced in the early mornings, evenings and night times.

Page | 19 
Low water pressure in domestic supply can be affected by seasonal changes in demand and supply, in addition to daily demand variation (OfWat, 2013). The water supply map produced by this study is not a definitive map for all times of day: it is likely to overestimate available supply at times of high demand and it does not take account of seasonal variation. However, the data about defective hydrants - very significant for vulnerability assessments - is not affected by temporal demand variations. The data collected in this study highlights the need for further investigation of firefighting water supplies including time-of-day variation and seasonal variation in water supply for firefighting.

\subsection{Implications for urban firefighting}

These findings have implications on firefighting resource allocation and tactics across London. In some circumstances, water supplies that are below the recommended levels will be sufficient to tackle a fire, however this is dependent on an incident commander being willing to deploy crews with a reduced weight of attack compared to standard operating procedures, potentially increasing risks to firefighters. Current policies and tactics, with the resources committed to fires in a pre-determined attendance format, assume an adequate local fire-hydrant water supply. This assumption and the appropriateness of policies, tactics and pre-determined attendances, are brought into question by the discovery that large areas of the study district have unreliable firehydrant water supplies. The extent to which this is the case across London region - and other urban areas with similar water supply systems for firefighting - should form the basis of further investigation.

\subsection{Operational adaptations to poor water supply}

Within the time taken to complete this study, some of the issues identified regarding poor fire hydrant water supply have been actioned by the LFB and Thames Water Utilities Ltd (known as Thames Water). New agreements with Thames Water mean that they will be notified by LFB of all fires that involve 6 or more pumping appliances. Thames water will then investigate the potential for remotely increasing the water supply to the affected area and will mobilise a Page | 20 
member of staff to attend the incident. However, the agreement notes that any increase in water supply will be at the discretion of Thames Water and is not guaranteed. It is recommended that this facility is extended to include any confirmed fires in areas identified as having severe Combined Vulnerability, based on the method presented in this paper. Further proactive steps taken by London Fire Brigade during the study period include adaptations to policies and tactics to allow greater flexibility to incident commanders and further investigation of variable water supply as a risk factor.

\subsection{Firefighting and water supplies in other countries}

In the literature on vulnerability and fire risk assessments, there is limited consideration of water supply vulnerability, with the focus instead on socio-economic vulnerability. This is true both in the UK, where the London Safety Plan 5 (London Fire Brigade. 2013d) identified areas of socioeconomic vulnerability, and in wider international research, internationally, a large body of research has examined socio-economic and demographic vulnerability factors, notably studies by Cutter (1996, 2003), Duga Rao (2005)., Write and Genna, (2005), Smith, Write and Solanki, (2007) and Govender, Barnes \& Pieper (2011). No studies were found that looked specifically at infrastructural vulnerability factors, such as mains water supply, with the exception of the work by Davis (2000). This study therefore offers a contribution to a broader understanding of fire vulnerability in an urban firefighting context.

Davis (2000) carried out a pioneering study in New Zeeland, comparing the times of the day when urban fires occur, with the water availability. Peaks in demand on water resources coincide with peaks in occurrences of fires, indicating that the times when firefighters are most likely to require fire hydrant water is when this water is least available. The fire risks highlighted by Davis (2000) in New Zealand are likely to be replicated in London. LFB fire data reflects the hourly pattern of operational of incidents, as shown in figure 9: the occurrence of accidental dwelling fires, as well as deliberate fires and accidental open land fires, peeks in the evenings. The evening is thus a time of high demand on the water main and subsequently one of poor Page | 21 
water availability for firefighting.

In water-stressed areas of Australia, New Zealand and the United States, the use of open water supplies for firefighting is common (e.g. ponds, lakes, streams and swimming pools), as are static water supplies adjacent to buildings, such as rainwater storage cisterns (Davis, 2000). In this study of Southall, open water sources were identified adjacent to several areas of high vulnerability. There is thus an opportunity for the LFB to investigate the use of open water sites to provide a long-term alternative to hydrant supply across London.

\subsection{Tactical and resource implications for London's firefighters}

The amount of water required to extinguish a fire is directly related to its size and that although the rate of growth is subject to many variables, a fire will continue to grow in size until all fuel or oxygen is consumed, or there is intervention by the fire service (Davis, 2003). Therefore the speed with which a fire service is able to make an intervention will have a large impact on the amount of water that will be required to extinguish the fire. In the context of limited water supplies, LFB should adopt rapid intervention tactics to reduce the impact of limited water supply on operational effectiveness. This may require LFB planners to re-examine recommended weights of attack for certain classes of incident.

LFB is currently undergoing a period of reduced financial resources, leading to the closure of fire stations and the removal of fire appliances (LFB, 2013d): efficient use of remaining response assets is essential. As a fire escalates, an inadequate water supply can draw in appliances from other areas. In the context of reduced resources, the implications from this type of incident for fire brigade business continuity are heightened.New tactics and resources are needed, to ensure rapid intervention, with sufficient water to prevent a fire escalating.

One such response bythe LFB is to increase the prevalence of sprinkler systems within dwellings, as these provide a rapid and water-efficient method of attacking a fire. This study also supports the wider use of open water supplies (such as lakes, canals and rivers) in fire service 
operations, training and planning. Furthermore, the London Fire Brigade has access to 6 bulk water carriers, each of which holds 14500 litres of water; these appliances are currently only available to incidents involving mass decontamination, rather than fires, and have a 4-hour attendance time (LFB, 2010). If these vehicles were brought into general service, the LFB could rapidly make large volumes of water available for incident commanders, allowing rapid intervention with high weights of attack, limiting the need for additional appliances to be sentfrom other areas. This would be particularly useful at large industrial sites with poor water supplies. According to Davis (2000), the use of bulk water carriers for firefighting is more cost effective than improving the domestic water main supply, to a level that supports high firefighting demands.

\subsection{5. Looking to the future: London's firefighting water supply and climate change}

London is currently one of the UKs most water-stressed regions, with water usage exceeding the local supply. The level of water stress is likely to increase because of projected growth in population, household size and population density (DEFRA, 2008). These changes in population, coupled with climate change, are expected to severely affect the supply of water in London during the summer months, which are projected to be both drier and hotter (DEFRA, 2008). Part of the long-term strategy of Thames Water, in response to water stress within London, is to reduce leakages by reducing water flow-rates and pressures across the water supply network (Macklin, 2006, LFB, 2012c). The implication of this is that water availability from fire hydrants within London is likely to reduce in the medium to long term, rather than to increase. This means that preparedness measures taken by the LFB that focus on fire hydrant supply, will be of limited usefulness in the future. The findings of this study, indicating that London's fire hydrant water supply is already inadequate, combined with likely increases in water stress in SE England, mean that the London Fire Brigade may have to consider long-term strategic changes to tactics, resources and planning. 


\section{Conclusions}

This study indicates that fire vulnerability within London has previously been underestimated, due to a focus on vulnerability assessments based primarily on socio-economic data. Fire hydrant water supplies were found to be inadequate to meet the likely demands of firefighting in significant parts of the study area, which increases the vulnerability of residents and businesses significantly. Within the study area, 13 areas of high combined vulnerability were identified within which land use type, water supply and socio-economic vulnerability interact to produce areas of increased vulnerability to fire. This study highlights that existing water supply problems are likely to worsen with time given climate change and population growth effects.

London Fire Brigade, and other metropolitan fire services in water-stressed areas, should include water supply variability in current risk mapping and planning. Fire services in water stressed areas will need to include long term reductions in water supply in their strategic vision, this will include a need to align tactics with water availability and to ensure the specification, procurement and positioning of future resources take account of variable and worsening water supplies. Within London water supply variability should be included as a specific variable within the next London Safety Plan (LSP-6).

This study presents an improved methodology for assessing urban fire vulnerability, which improves on existing methods by including of information on land-use and water supply. Water flow-rate recommendations for firefighting were combined with flow rates required by the weights of attack stipulated by London Fire Brigade to determine the sufficiency of water supply for fighting fires in different types of land-use. A review of the literature revealed few methods for calculating water requirements for extinguishing fires, outside of controlled fire-engineering contexts, which are inappropriate in the varied and often complex operational environments of London. By using this mixed method, London Fire Brigade policy on sufficiency of water supply was taken into account, alongside the risk assessment recommendations of the Local Government Association and Water UK. 
This is the first time that fire risk assessments have been able to utilise a combined map showing land use vulnerability, water supply vulnerability and socio-economic vulnerability. The findings of have implications for the London Fire Brigade in their planning, tactics and resource allocation, with the GIS-generated maps presented here, enabling evidence-based discussion on policy. The methodology can be used as a template for further study and for producing combined vulnerability maps for the rest of London, with scope to apply the methodology to other cities.

\section{References}

BBC, (2012) London Fire Brigade warns of 'beds in sheds' fire hazards. Retrieved from http://www.bbc.co.uk/news/uk-england-london-19800791

Benfer, M.E., and Scheffey, J.L. (2014) Evaluation of fire flow methodologies. Fire Protection Research Foundation, Fire Research Report, 57pp.

City of Kent. Washington. (2010) Hazard Identification and Vulnerability Analysis - Urban Fire. Retrieved from http://kentwa.gov/content.aspx?id=8058

Cutter, S.L. (1996) Vulnerability to environmental hazards. Progress in Human Geography, 20(4), 529-539.

Cutter S.L., Boruff, B.J. \& Shirley, W.L. (2003). Social vulnerability to Environmental Hazards. Social Science Quarterly, 84 (2), 242-261.

Dalrymple, A. (2007). Cost of fire conference paper May 2007. Reducing water pressure: what are the implications? Retrieved from: http://www.conferenceworld.com.au/resources/other/ 12\%20Adam\%20Dalrymple\%20Wed\%20am\%20paper\%202.pdf

Davis, S. (2000). Fire Fighting Water: a Review of Fire Fighting Water Requirements. a New Zealand Perspective. Fire Engineering Report 2000/3, University of Canterbury, Christchurch.

Durga Rao, K.H.V. (2005) Multi-criteria spatial decision analysis for forecasting urban water requirements: a case study of Dehradun city, India. Landscape and Urban Planning, Volume 71, Issues 2-4, 163-174. doi:10.1016/j.landurbplan.2004.03.001

Gilmore, P. \& Smith, I. (2012). Outhouse Project. London: Ealing Council Regulatory Committee.

Govender, T., Barnes, J. \& Pieper, C. (2011). The Impact of Densification by Means of Informal Shacks in the Backyards of Low-Cost Houses on the Environment and Service Delivery in Cape Town, South Africa. Environmental Health Insights. 5, 23-52.

Grimwood, P.(2014) In full flow. FRM Journal, DECEMBER 2014 / JANUARY 2015, 28- 
32.Local Government Association \& Water UK. (2007). National guidance document on the provision of water for fire-fighting. London: TSO.

London Fire Brigade, (2011c). Firefighter development programme stage 1. Module 2. Session code: M2.12. Introduction to dual-purpose pump ladder. Unpublished internal document. London Fire Brigade. (2001, 25th January). Hydrants and water supplies for firefighting. (Policy number 317). Unpublished internal document.

London Fire Brigade. (2007, May). Accidental fires in the home. (LFB thematic report No.7). Unpublished internal document.

London Fire Brigade. (2008a, $26^{\text {th }}$ November). High rise firefighting. (Policy Number 699). Unpublished internal document.

London Fire Brigade. (2008b, $16^{\text {th }}$ October). Branch Hosereel - TFT Ultimatic FO7-technical information. (Policy number 691) Unpublished internal document.

London Fire Brigade. (2008c, May) Secondary Fires. (LFBthematic report No. 12). Unpublished internal document.

London Fire Brigade. (2010, 30 ${ }^{\text {th }}$ September). Bulk water carrier - BWC. (Policy number 730). Unpublished internal document.

London Fire Brigade. (2011a, $18^{\text {th }}$ November) Firefighting in basements. (Policy Number 773) Unpublished internal document.

London Fire Brigade. (2011b, $8^{\text {th }}$ April) Home Fire Safety Visits. (Policy Number 741) Unpublished internal document.

London Fire Brigade. (2012a, $3^{\text {rd }}$ October). Compartment Firefighting. (Policy Number 793) Unpublished internal document.

London Fire Brigade. (2012b, $11^{\text {th }}$ October). Branch - Rosenbauer Select Flow RB $101-$ technical information. (Policy number 811). Unpublished internal document.

London Fire Brigade. (2012c, July) Provision of water supplies. Operational News Issue 23. 1-3 London Fire Brigade. (2013b).Targeting those most at risk from fire: Fifth London Safety Plan Supporting document No.5. Retrieved from: http://www.london-fire.gov.uk/Documents/Sup05Targeting-those-most-at-risk-from-fire.pdf

London Fire Brigade. (2013d). London Safety Plan 5. Retrieved from: http://www.londonfire.gov.uk/Documents/LSP5-authority-version-18-july-following-september-authoritymeeting.pdf

Ofwat (2013). Water Pressure. Retrieved from:

http://www.ofwat.gov.uk/consumerissues/rightsresponsibilities/waterpressure/

Rogers, C. (2012). 'Sheds with beds' are London's modern day slums. BBC News. Retrieved from: http://www.bbc.co.uk/news/uk-17185294; $27^{\text {th }}$ February 2012.

Page | 26 
Sardqvist, S. (1996). An engineering approach to fire-fighting tactics. (Report No. 1014). Lund: Lund Institute of Technology Department of Fire Safety Engineering.

Smith, R., Wright, M. \& Solanki A. (2007). Analysis of fire and rescue service performance and outcomes with reference to population socio-demographics. (Fire Research Series 9). London: Department of Communities and Local Government.

UK Department for Communities and Local Government (2011). Fire and Rescue Service operational Guidance. London: TSO

UK Department for Communities and Local Government. (2008). Final report to Communities and Local Government: Fire Research Series 13/2008. London: TSO

UK Department for Environment, Food and Rural Affairs (2008). Future Water: The Government's water strategy for England. London: TSO

UNISDR. (2007). Terminology. retrieved from UNISDR website: http://www.unisdr.org

Wright, M. \& Genna, R. (2005). Identification of risk measures for use in F\&RS funding formula. (First Interim Report to Office of the Deputy Prime Minister). Reading: Greenstreet Berman Ltd. 